\title{
A Development Of Logistics Management Models For the Better Customer Service
}

\author{
Dr Manjusmita Dash \\ P.G. Department of Business Administration, \\ Utkal University, Vani Vihar, Bhubaneswar-751004. \\ Odisha, India.
}

\section{INTRODUCTION}

Logistics management is a supply chain management component that is used to meet customer demands through the planning, control and implementation of the effective movement and storage of related information, goods and services from origin to destination. Logistics management helps companies reduce expenses and enhance customer service. Logistics management in India has become complex with about ten million related outlets to cater to the needs of 1000 million people. At the micro level any manufacturing and marketing company spends 5-35 percent of sales on logistics and in fact 10-15 percent of product cost is logistics related. For any country, the logistics cost is estimated between 8 to 20 percent of its GDP. In India logistics cost is $13 \%$ of the GDP as compared to $8 \%$ in USA. The higher costs arise due to level of inefficiencies in the logistics network, which can be sagaciously considered to be configured in this phase of global melt down and recession to ensure fastest service with economical cost.

\section{REVIEW OF LITERATURE}

Mathematical programming models offer a relatively tractable alternative approach to 'closed form' solutions for solving the location\}consolidation problem. Further, as noted by Bowersox and Closs [1996.], the modeling flexibility provided by the mixed-integer programming approach makes it particularly suitable for incorporating the complexities that arise in logistics in general and transportation in particular. Recent instances of mathematical programming approaches to the inbound consolidation problem include Russell and Krajewski [1992], and Syam and Shetty [1996].

However, these studies are confined to relatively simple environments involving only a single destination rather than multiple destinations, and supplier(s) with pre-determined rather than undecided locations. Further, both of these papers were concerned with single-echelon networks, rather than bi-echelon networks including warehouses, as in the current research. This paper significantly extends previous work in inbound consolidation by using a mathematical programming approach that seeks to simultaneously and optimally determine (i) the locations of multiple plants and (ii) the composition and timing of shipments and (iii) flows between multiple plants, warehouses, and destinations.

Khumawala (1972) introduced mixed integer programming formulation of the warehouse location problems with an efficient branch and bound algorithm. According to Khumawala, Effroymson and Ray (1966) had earlier applied branch and bound technique to calculate optimal solutions for warehouse location problems. But, his technique is drastically more efficient, as he put it. The first improvement was setting a branching decision rule at every level in order to select an available warehouse location from the overall set of available 
locations. The second improvement was about managing the integer variables. Initially, by using this technique the algorithm was solved as if it was a linear program.

Mixed integer programming was revisited by Melachrinoudis and Min (2007). This time the objective was to redesign a warehouse network in order to minimize total supply-chain cost including production, transportation, warehousing and relocating costs, and at the same time to maximize the closure and/or consolidation of the unnecessary warehouses. In other words, the program was constructed in order to optimize a given warehouse network by simultaneously eliminating redundant (existing) warehouses and locating new potential warehouse. Their mathematical formulation took into account certain restrictions such as: production capacity of the plants, supplying of all customer demand and serving every customer in a given time frame.

Related work about simulation techniques for warehousing networks can be found in Williams and Gunal (2003). This study presented a general summary about a commercial logistics simulation software package, called SimFlex. As a matter of fact, this software tool was claimed to be capable of dealing with location, manufacturing, transportation, procurement, distribution, sales and tradeoff problems. In the given case study, manufacturing facility and distribution center locations were specified to the model with inventory control policies and customer demand data. Furthermore, product types and their hierarchical constituent particles were fed along with logistic services and delivery policies. Some other variables were also allowed in the model, such as, processing times and shipment costs. The process of planning, implementing and controlling the efficient, cost-effective flow and storage of goods and materials as well as related information, from the point of origin to the point of consumption for the purpose of meeting the end beneficiary's requirements." (Thomas and Mizushima, 2005).

\subsection{Facilities}

\section{DEVELOPING LOGISTICS NETWORK MODEL}

Facilities are the foundation of the supply chain infrastructure and include suppliers, plants, distribution Centres, and customers. Figure below illustrates facility data that is needed or useful in logistics modelling.

\begin{tabular}{|c|c|c|c|}
\hline Supplier & Manufacture & Warehouse & Customer \\
\hline $\begin{array}{l}\text { material types } \\
\text { purchase prices } \\
\text { available quantities }\end{array}$ & $\begin{array}{l}\text { types of products } \\
\text { production costs } \\
\text { production capacities } \\
\text { production rates } \\
\text { expansion costs }\end{array}$ & $\begin{array}{l}\text { types of products } \\
\text { throughput costs } \\
\text { storage costs } \\
\text { throughput capacities } \\
\text { storage capacities } \\
\text { expansion costs }\end{array}$ & $\begin{array}{l}\text { types of products } \\
\text { quantities needed } \\
\text { selling price } \\
\text { service requirements }\end{array}$ \\
\hline
\end{tabular}

Fig 3.1 Facility data in logistics modeling

Geocoding is the process of determining the geographic (longitude and latitude) coordinates or geocodes of a facility, given a description of the facility. The description of a location could be a street address, city name, or postal code.

Geocodes are needed for many types of quantitative analysis tools where nearness among facilities is important, such as the routing of vehicles or the location of new facilities. Geocodes also allow the logistics supply chain to be visually represented using map-based graphical user interfaces. 


\subsection{Facility Zones}

Zones define the geographical territories of facilities, such as sales regions, customer territories, or distribution center areas. Zones can be pre-determined (such as marketing territories) or can be created automatically by rules or algorithms. Figure 29 illustrates example zones defined for a set of customers - individual customer data such as demand is aggregated to determine total demand by zone.

Facility zones play an important role in simplifying a logistics model, as aggregate regions can represent the demand of hundreds or even thousands of individual customers. Effective zones usually define logical geographical clusters of facilities, adjusted to balance some attribute (such as total zone demand or transportation workload, for example).

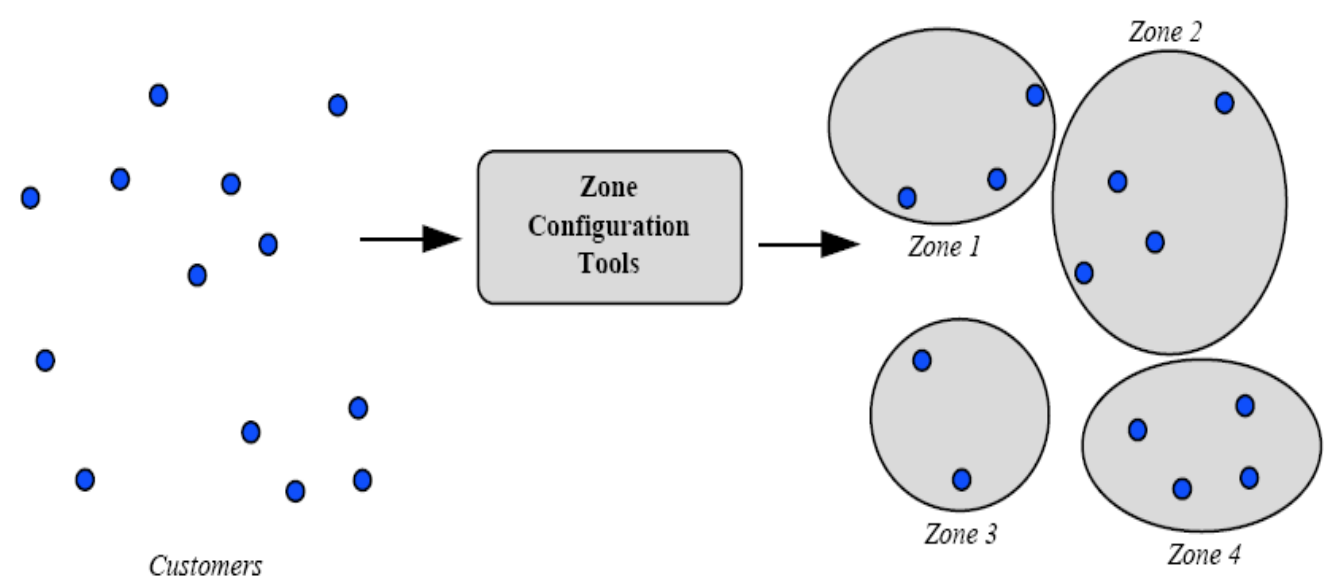

Fig 3.2. Facility Zones

\subsection{Shipping Lanes}

Shipping lanes are the product movement connections between supply chain facilities. Figure below illustrates shipping lane data relevant in logistics modelling.

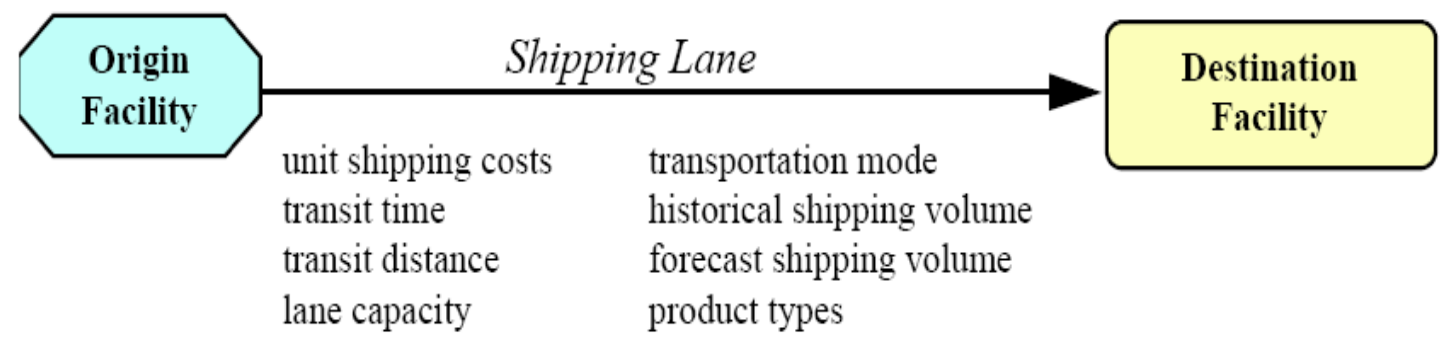

Fig 3.3. Shipping Lane

Shipping lane generation defines the shipping lanes between facilities that are candidates for product flow. Lane generation tools help to pare down the large number possible transportation lane combinations to a practical or logical set. These candidate lanes are inputs to analytical tools deciding actual product flows and schedules.

Shipping lanes can either be pre-determined or generated by rules or algorithms (such as all lanes of distance less than 500 miles, or by product compatibility issues). Figure 31 illustrates example lanes generated between facilities. 


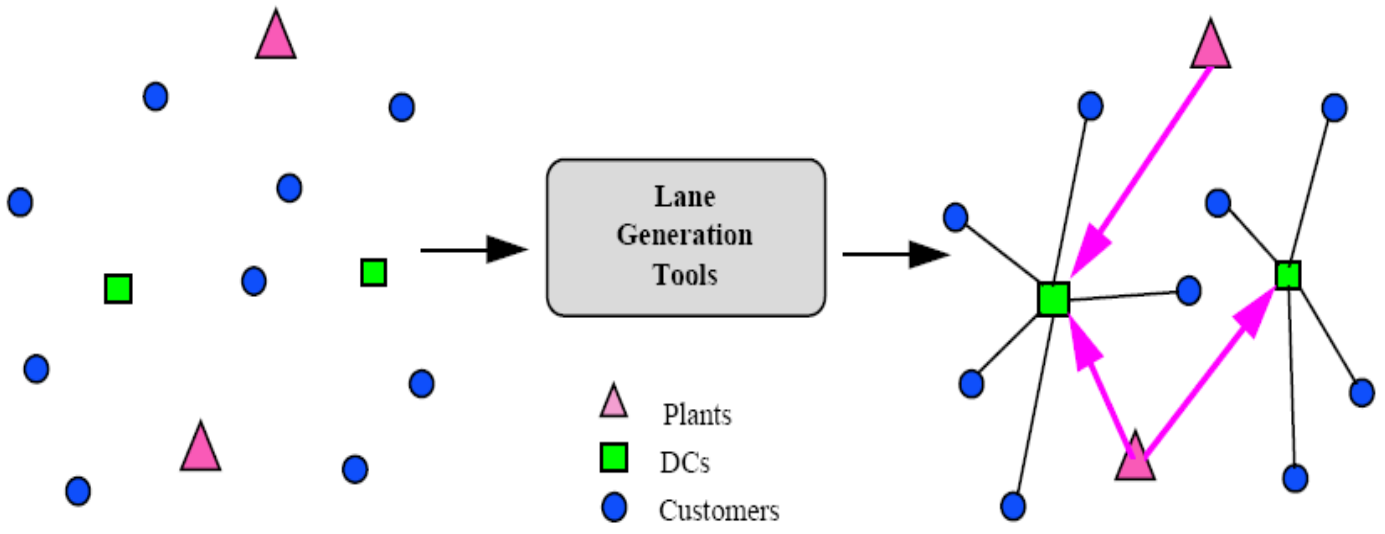

Fig 3.4. Lanes between facilities.

\subsection{Representing Movement Requirements}

Movement requirements indicate product demand or shipments, including when and how many products or components are needed at specific facilities or zones. One way to indicate movement requirements is to specify the aggregate supply and demand for products at facilities or zones.

Aggregate supply-and-demand models are appropriate where the origins and/or destinations of movements are unknown. Aggregate models are also useful for answering strategic design questions.

Another fundamental way to represent movement requirements is to describe explicit shipments, including origins, destinations, products, volumes, due dates, and pickup dates. Origin-destination shipment models are useful for answering routing and scheduling questions involving explicit shipments and transportation assets.

\subsection{Representing the Flow of Shipments and Assets}

Logistics objects that are moving include shipments and transportation assets. Paths and routes are used to represent the movement of goods and transportation equipment among facilities. Schedules describe timing information associated with the movements. Figure illustrates examples paths, routes, and schedules. Note transportation assets include trucks, drivers, and trailers, each with possibly distinct routings and schedules. 


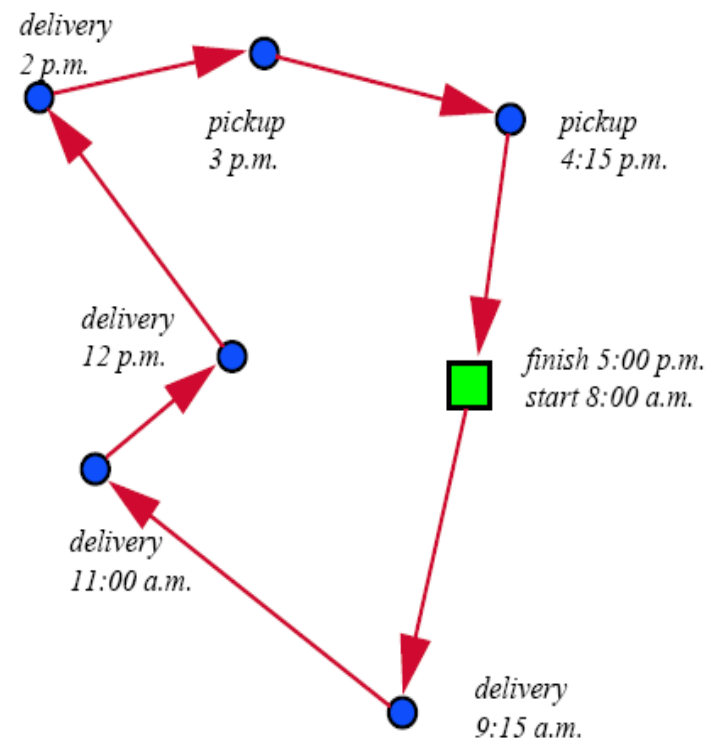

Vehicle route \& schedule

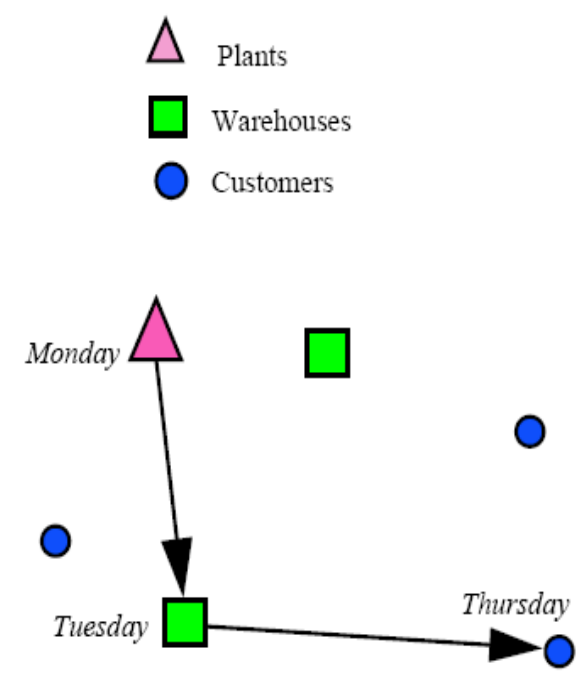

Shipment route \& schedule

Fig 3.5. Path, route and Schedule

\subsection{Other Data Issues}

\section{Sources of Data}

Data for logistics objects can be generated in three basic ways:

\section{Current information.}

Some logistics models are based on current logistics information. For example, vehicle dispatching models need information about today's orders, vehicles available, driver status, etc.

\section{Forecasts.}

Other models are based on forecasts of future information - historical data is used to predict future customer demand, available production capacity, etc. The estimates can be generated in a variety of ways, from using sophisticated forecasting algorithms to simply rolling up a year's worth of historical data to give an annual view of a supply chain.

\section{Historical information.}

Still other models use actual historical data to calibrate model accuracy - model outputs can be compared to what actually happened to ensure the model is a valid representation of the logistics supply chain.

\section{Time-related Data: The Modelling Horizon}

A key modelling issue is defining the time span or horizon of a logistics model. Some models are single period models - there is only one time period, so data in these models does not change over time. A popular single-period model is a one-year view of a supply chain, with relevant facility data including the total production capacity or demand forecast for the entire year. Single-period models are useful for analyzing solutions to strategic design models.

In contrast, some models are multi-period models, with data potentially changing from one time period to the next. For example, the customer demand for soft drink products increases during the summer months. A popular multi-period model is a one-year view of a supply chain by month, with relevant facility data including the production capacity or demand forecast for each month, for example. Multi-period models are useful for analyzing solutions to resource scheduling models. 


\subsection{Evaluating Alternatives}

\subsubsection{Introduction}

Evaluating Alternatives is "playing out" or simulating the operation of a logistics supply chain using a model and analyzing the attractiveness of the supply chain configuration. Cost and service performance measures, resource utilizations and bottlenecks, and other statistics of the logistics system are calculated in this phase of $L C M$.

Evaluating Alternatives is composed of the Evaluate, Benchmark, and Rationalize steps, each geared towards answering particular analysis questions. These three steps combined with the Generate Alternatives step form an iterative analysis cycle, illustrated in Figure. The analysis process is naturally iterative because evaluating one alternative often suggests new alternatives to investigate.

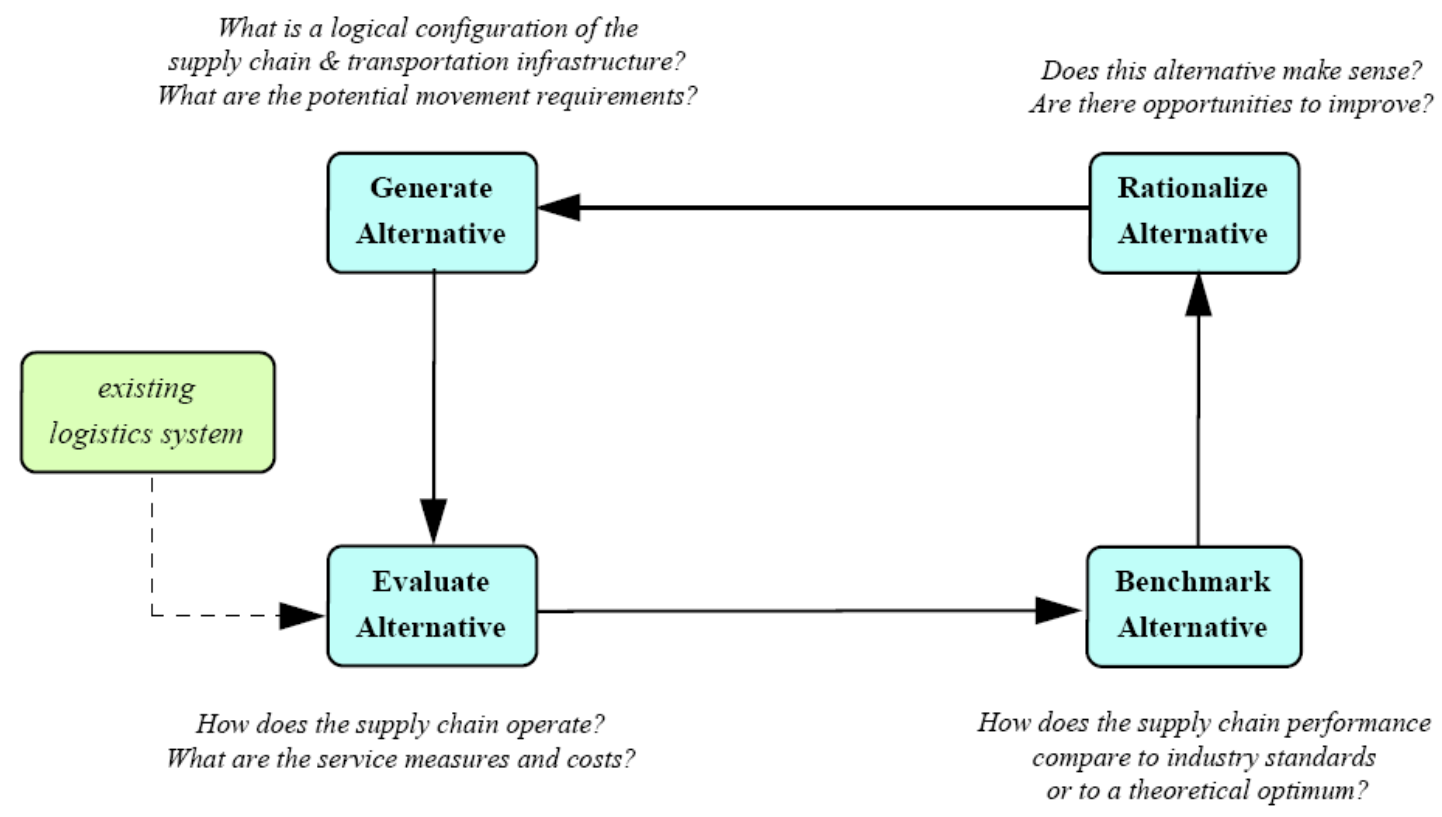

\subsubsection{Model Simplification}

Fig 3.6. Generation of Alternatives steps

Logistics supply chains can be very large systems composed of hundreds of facilities moving tens of thousands of products or more. These systems are far too large and complex to work with all at once in the Generate, Evaluate, Benchmark, and Rationalize steps. The only practical way to analyze and improve a logistics system is to simplify the logistics decisions into smaller interrelated and manageable components. Two model simplification techniques are aggregation and partitioning.

\subsubsection{Model Aggregation}

Aggregation is collecting or "rolling up" related data up to a simpler or more approximate representation. Examples of logistics supply chain aggregation are the following:

- Grouping individual products or stock-keeping units (SKUs) into product families, representing groups of similar product items.

- Adding up the individual product demand for customers to get the total demand by customer zone.

- Adding up the manufacturing capabilities of individual production lines and assembly stations into a total production capacity or a manufacturing plant.

- Representing large numbers of individual truck trailers by a few basic trailer types, such as refrigerated, 48 foot, etc. 


\subsubsection{Model Partitioning}

Another way to simplify a logistics system is to decouple or partition the supply chain into more manageable components. For example, we could divide the distribution system into regions, and develop vehicle routing models separately within each region. Of course, a key part of supply chain modeling is treating the logistics system as an integrated process, so care must be taken to provide enough "linkage" between the components to capture the relevant decisions and issues.

\subsubsection{Model Accuracy}

In the ideal logistics model:

- All data is available and correct.

- There is no error in forecasts of future data (including customer demand, availability of supply, availability of resources, etc.).

- The model exactly captures all of the relevant issues in the logistics supply chain.

Unfortunately, in most situations some data is missing or incorrect, the forecasts of future data are wrong, and some supply chain characteristics are too fuzzy to capture precisely in a model. Thus most logistics models are at best approximate representations of the actual logistics system.

How do we know if an approximate and simplified model is an accurate representation of the logistics supply chain? This is the heart of the Evaluate Alternatives step. This modelling step "plays out" a given logistics system configuration, so more detailed data can be used. The result is that baseline statistics can be calculated and used to gauge the precision of more simplified models.

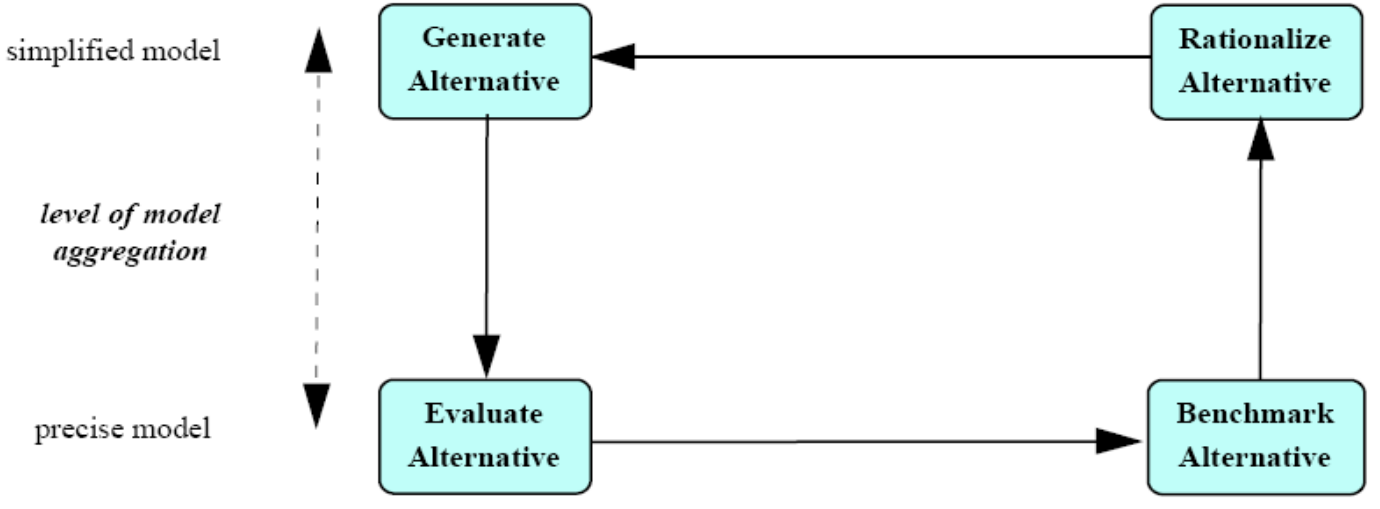

Fig 3.7. Level of model aggregation

For example, in aggregate models it is common to use average or approximate values for costs and demand quantities. Given the movement of actual shipments, we can evaluate the true shipping costs and compare with the approximate costs. We can then modify and improve how we estimate the approximate costs and demands based on what actually happened. Thus the evaluation step measures the accuracy of a simplified model.

Simplified models are particularly useful in the Generate step, as solution generation tools can examine a greater number and variety of decision alternatives using more aggregate models. It is important to note that the output of the Generate phase is the input to the Evaluate phase. For example, the optimal solution generated by a mathematical optimization model is not necessarily the "answer" but rather must be played out and evaluated to judge the solution's true attractiveness. More aggregate model views are also useful in the Rationalize step, as these models are easier to understand and manipulate. 


\subsubsection{Costing}

The process of determining the product cost delivered to the customer forces the specification of cost models for the various components of the entire logistics supply chain. The cost to deliver a unit of product to the customer is called the landed customer cost. Figure below illustrates the various types of costs incurred as a product moves through a logistics supply chain. The result is the cost to get a product to two different customers is almost always different.

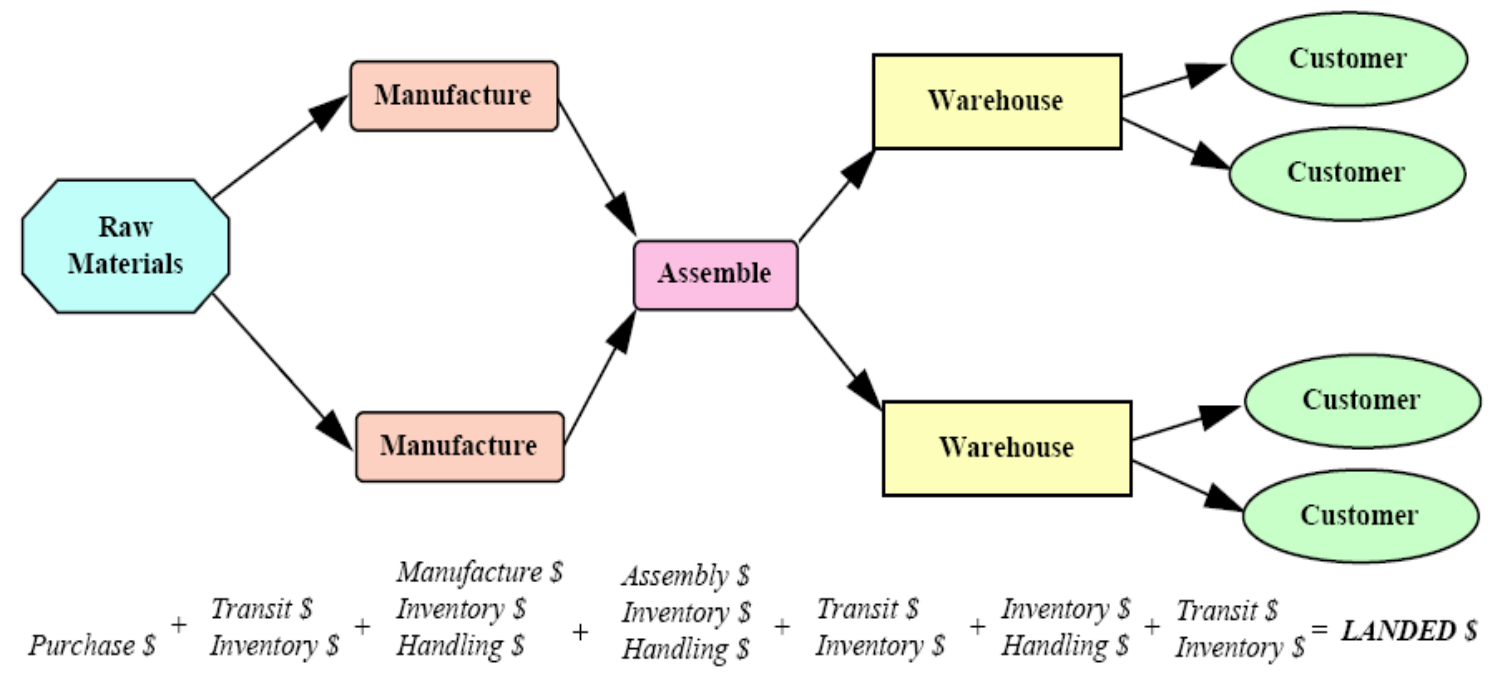

Fig 3.8. Costs incurred when a product moves

Some cost components are easy to determine for specific products and customers, but other costs are shared among products or customers and must be fairly allocated. Activity-based costing is one allocation method that attempts to accurately allocate resource costs by focusing on the activities performed by the resources.

Costs are then allocated based on the activity levels needed by individual products or customers. For example, we could allocate the cost of a vehicle route over a set of customers by first identifying specific route activities, such as driving, loading, and unloading. Some activities are tied to individual customers (such as unloading), and thus the corresponding costs are easy to allocate. Other activities (such as driving) are jointly influenced by customers and must be allocated using some estimate of an individual customer's contribution to the activity.

\subsubsection{Benchmarking and Rationalization}

Benchmarking is comparing the performance of a logistics supply chain to organizational or industry standards or to some theoretical "ideal." If data is available, it may be possible to compare the supply chain to so-called "best-practice" standards or corporate supply chains that are recognized as industry leaders in logistics operations.

Benchmarking metrics generally fall into two basic groups: costs; and service measures. Sometimes costs and service measures can be measured directly, but frequently surrogate indicators must be used to estimate performance (particularly for service). For example, the inventory turnover rate, the total cycle time of a product in a supply chain, and the movement accuracy (timeliness of actual shipment movements compared to predicted movements) are commonly used as estimates of the level of customer service provided by the supply chain. In general, the more surrogate the metric, the more carefully it should be treated when evaluating supply chain performance. 
The Rationalize step is the interpretation of the Evaluation and Benchmark results, and the justification of the logistics supply chain configuration. Tools to use in this step include cost reports, service metrics, and the utilization of resources. Model aggregation is important in this step, as it is important to see the "big picture" of the logistics supply chain and focus on the key opportunities for improvement. Rationalization relies heavily on strong graphical user interfaces that can illuminate resource bottlenecks, high cost elements, service problems, etc.

\subsection{Generating Alternatives Introduction}

Generating Alternatives includes any change to the logistics strategy, supply chain infrastructure, transportation infrastructure, movement requirements, or the relevant operating parameters. There are four fundamental ways to generate logistics supply chain alternatives:

○ Existing system. If the logistics supply chain already exists, then the first alternative analyzed is the current system, and the analysis proceeds directly to the Evaluating Alternatives phase.

- Specified. The alternative to investigate could be given, such as a strategic plan that the organization's management would like to evaluate.

- Automatic. The alternative could be generated automatically, using computer algorithms based on mathematical optimization, heuristics, rules, etc.

- Interactive. The alternative could be generated interactively, in an exploratory or "what-if" style.

\section{Automatic Generation of Alternatives \\ Mathematical Optimization}

One of the most important steps of LCM is developing an analytical or mathematical model of the logistics supply chain. An analytical representation is natural because of the many quantifiable elements in logistics (such as shipping costs, storage costs, transit times, inventory levels, production capacities, and demand forecasts). Mathematical optimization is a powerful class of quantitative models, tools, and algorithms that can be used to automatically generate and examine vast numbers of decision alternatives and pinpoint smart alternatives.

A mathematical optimization model consists of the following three components:

- Objective. Usually we wish to maximize or minimize some quantifiable goal. For example, common logistics objectives include maximizing profitability, minimizing landed costs, maximizing on-time shipments, or minimizing the number of trucks needed.

- Decision Variables. Decision variables represent choices in a logistics supply chain. For example, common logistics decision variables include where to locate facilities, how to route freight, and when to send shipments.

- Constraints. Constraints represent restrictions or requirements of the logistics supply chain. For example, common logistics constraints are storage space in a warehouse, available manufacturing capacity at a plant, the number of trucks available, and the shipment delivery time required by a customer.

\section{Easy" Optimization Models}

Some mathematical optimization models are "easy" in the sense that there are algorithms available that can consistently find the optimal solution in a predictable amount of time. The most useful models in this class are linear programming (LP) models. In an LP model the objective and all constraints are linear equations, and all decision variables are "continuous" (i.e., fractions are okay). Very large linear programs with tens of thousands of decision variables or more can be optimized quickly using efficient computer algorithms. 
A special class of linear programs are network linear programs which have many natural applications in modelling supply chain networks. Minimum cost network flows, shortest paths, and matching tools belong to this class, and have applications in resource allocation, production scheduling, and supply chain design.

\section{"Hard" Optimization Models}

Some mathematical optimization models are "hard" in the sense that there are algorithms available that can consistently find the optimal solution in a reasonable amount of time, if the problem size is sufficiently small. Thus these are "limited size solvable" models. For these models we can optimize small problems but either cannot optimize large problems or cannot solve them with consistency.

Many of the most important logistics models fall into the "hard" class. This includes most models of vehicle routing and scheduling, facility location and sizing, shipment routing and scheduling, freight consolidation, and transportation mode selection. These problems can be represented as mixed-integer programming models, a class of models with some of the decision variables restricted to integer values.

For example, the number of drivers and trucks assigned to drive a certain distribution lane could be $0,1,2$, etc., but could never be 2.7; a manufacturing plant can either be constructed or not constructed, but not partially built.

Mixed-integer models are often difficult to optimize, as there may be an exponential number of possible decision alternatives. For example, the number of possible combinations of opening or closing $n$ distribution centers is $2 \mathrm{n}$. There is no algorithm available which can guarantee finding the optimal alternative without the possibility of examining many of these alternatives. A further complication is the effort required to solve a mixed-integer program is often dependent on the specific problem data, and a very slight change to a model may transform a solvable problem to an unsolvable problem. Thus mixed-integer programming models are often better suited for planning when there is sufficient time to use alternative approaches if the solution effort becomes too great.

\section{Heuristics}

Heuristics are another important class of methods for automatically generating supply chain alternatives and decisions. A heuristic is simply any intelligent approach that attempts to find good or plausible solutions. The heuristic may be based on mathematical optimization, rules, or any other method that can generate alternatives.

The word "heuristic" sometimes implies a "seat-of-the-pants" solution approach, with little or no intelligence or sophistication used to make decisions. This is unfortunate, as analytical heuristics can be as technically sophisticated as mathematical optimization approaches. Many heuristics are actually based on mathematical optimization methods and algorithms such as using practical rules to formulate a mathematical optimization model. A powerful heuristical approach is to modify a mixed-integer program by temporarily treating the integer variables as linear variables, creating an approximate but much more solvable logistics model. The solution to this problem is then used as a basis for constructing a solution to the integer program.

\section{Distribution Channel}

Distribution channel management is very critical for the firms when they decide to enter one or more markets. Distribution channel structures are not difficult to change; however, primary wrong decisions might lead to dreadful results for the organizations. In accordance with 
Gattorna and Walters (1996), depict that distribution channel management follows a structured approach, using criteria which help to evaluate optional channel structures during which alignment (compatibility), trade-offs and channel relationships are considered. Increasingly, the roles of logistics service firms are included in the decision process for distribution channel, especially when they are a dominant element within the supply chain.

As Jobber (2001) mention, all products whether consumer products, industrial products or services require the use of distribution channel. To describe more about distribution channel, Etzel, Walker and Stanton (2004) present that a distribution channel consists of the group of people and firms involved in the transfer of title of products move from producer to final consumer or business user. According to Coelho et al., (2003), most international firms would prefer to run a direct channel distribution however instead the firms themselves are forced to use intermediaries and most distribution channels consider and consist of middlemen, but some do not (Etzel et al., 2004)

A channel that has only producer and final customer, with no middlemen providing assistance is called "direct distribution", whereas a channel of producer, final customer, and at least one level of middlemen represents "indirect channel" (Etzel et al., 2004).

\subsection{Warehousing and Distribution Center}

Warehouse and distribution center (DC) are very important nodes in a supply chain network; they perform valuable functions that support the movement of materials, storing goods processing products, deaggregating vehicle loads, creating stock keeping unit assortments, and assembling shipments (Langevin \& Riopel, 2005). These are the activities commonly performed in warehouses and distribution centres. The major challenge to DCs and warehouse, both today and tomorrow, is related to workforce issues, for example, staffing, training, scheduling and job design (Ackerman \& Brewer, 2001-cited in Kotzab \& Bjerre, 2005). Moreover, firm must also consider facilities that help the firm to cut handling costs.

Coyle at el. (2003) present the definition of warehousing and distribution center that warehousing is the storage of goods, whereas distribution center precedes a post-production warehouse for finished goods held for distribution. Therefore, warehousing and DC basically have the same function which is goods and products storage. According to Higginson and Bookbinder (2005), a distribution center is in fact, a specific type of warehouse" as well as Frazelle (2002) who refers distribution center as distribution warehouse.

\subsubsection{Warehousing}

New cars can be stored outside on the dealer's lot, fuel oil can be stored in a specially designed tank, coal and other raw material can be stored in open pits but most products must be stored inside protective building (Perreault \& McCarthy, 2003). According to Higginson and Bookbinder (2005), "Warehouses store all products in four cycle (receive, store, pick and ship)". Firm can decide and select among the different kinds of specialized storing facilities, and the right choice might assist the firm reducing costs and serving customer better (Perreault \& McCarthy, 2003). The use of specific type of these storing facilities is aimed to reduce/cut costs and smooth the distribution as well as operation to enhance service level to the customer.

Private warehouses is a storing facility owned or leased by the company for its own use, additionally, most manufacturers, wholesalers, and retailers have some storing facilities whether in their main building or in different separate location (Perreault \& McCarthy, 2003). In the eyes of Perreault and McCarthy (2003) depict that firms use private warehouse when a 
large volume of goods and prodcuts must be stored regularly, nonetheless private warehouse can be expensive in dealing with the changes needs as It might be difficult or impossible for the extra space to rent to others.

Public warehouse is an independent storing facility. Public warehouse usually provides all services that a company's own warehouse can provide (Perreault \& McCarthy, 2003). They also cite that public warehouses are functional and useful for manufacturers who are required to maintain stock in many different locations. The first and most significant reason for using public warehouse is financial; it requires no or limited capital investment by the company (Coyle et al., 2003)

\subsubsection{Distribution Center}

Perreault and McCarthy (2003) state that a distribution center is a special type of warehouse which been designed to fasten the flow of goods and avoid unnecessary storing goods. Today the distribution center concept is widely used by firms at all channel levels and also manyproducts buzz through a distribution center without ever tarrying on a shelf, workers and equipment immediately sort the products as they come in hand subsequently move the products to an outgoing loading dock, and then to the vehicle which will take the products to next stop (Perreault \& McCarthy, 2003). Seeing the information latter distribution centre speeds up the distribution process and reduces the complication in storing goods.

According to Higginson and Bookbinder (2005), DCs handle most products in two ways, receiving and shipping rather than storage and also DCs hold minimum inventories and of predominantly, high-demand items. Nevertheless many of works cited use interchangeably the two terms, warehouse and DC.

Since the 1980s, three supply-chain trends have had a major impact on the distribution center (Higginson \& Bookbinder, 2005)

- Reduction in the number of warehouse;

- Greater emphasis on the flow of goods rather than their storage;

- Increases outsourcing of warehouse/distribution center activities.

\subsubsection{Warehouse/DC Operational and Facilities}

The basic warehouse operations are movement and storage (Coyle et al., 2003).The cost of physical handling is a major storing cost. Moreover goods must be handled once putting them into storage, and removing them again when they are to be sold (Perreault \& McCarthy, 2003). Warehouse also includes highly specialized storage facilities such as bean and grain elevators and refrigeration facilities etc (Coyle et al., 2003) as well as distribution center. In this chapter, the authors will use warehouse and distribution center interchangeably.

Both simulation and optimization/heuristic models are needed to meet the challenges of the transportation and logistics/supply chain problems of today and the future. Simulation packages need to incorporate logistics and transportation constructs and terminology to facilitate model building in a more natural and easier manner. Finally, to leverage the strengths of both types of models, the design packages using optimization and heuristic methods could share a common representation of the network and other fundamental transportation, logistical and supply chain parameters so as to facilitate simulation for design evaluation and validation. 


\section{Mathematical model and item consolidation}

The logistical framework and its mathematical representation are presented in this section. The section also contains a discussion of the manner in which the decision variables of the model facilitate inventory consolidation, an objective of the research.

\subsection{Logistical framework}

The logistics model encapsulates the functioning of a multi-commodity freight network, consisting of plants, intermediate warehouses for inventory consolidation, and "final destinations. In this paper, a plant is sometimes referred to as a manufacturing facility', and a link between two points in the network is occasionally referred to as an 'arc'. In common with the freight network and inbound consolidation literature, the term \&cycle time' refers to the frequency with which a good or group of goods is shipped- once a year, twice a year, etc. The objective is to determine locations, flows, groups of commodities, and their associated cycle times so as to minimize total logistics cost, comprised of inventory holding, purchase order line-item, purchase-order header, transportation, manufacturing, material handling, and "fixed costs at plants and warehouse. The constraints of the model impose various logistical requirements - for instance, that the demand for each good at each destination must be met, that freight rates are a piecewise function of volume and shipment weight, that each facility is subject to certain capacity limitations, etc.

\subsection{Model structure}

In the mathematical model that follows, the objective function comprises the following components:

(i) Inventory holding costs (ii) ordering line-item costs (iii) ordering header costs (iv) transportation costs (v) manufacturing costs (vi) material handling costs at warehouses (vii) fixed costs at plants (viii) "fixed costs at warehouses. Ordering costs, which are incurred when an order is fulfilled, consist of a "fixed (header) charge for each order and additional line-item charges for individual items. Inventory holding costs in the model are computed as "fixed percentages of item values. Plants di!er in unit manufacturing costs of items and "fixed costs, and material handling costs vary from warehouse to warehouse, as do the "fixed warehouse costs. All costs are considered on an annualized basis. Transportation costs are incurred on all links and are modelled to capture freight rates that vary as a function of shipping distance and shipment weight.

In the model, constraint (1) ensures that the demand for each item at each destination is met, and constraint (2) imposes the capacity limitations at each facility by commodity (equal to zero if the facility is not open). Constraint (3) imposes material-handling capacity limits on each warehouse by commodity (equal to zero if the warehouse is not open). Constraints (4) and (5) impose freight rates on shipments according to weight. Constraint (6) ensures that at most one freight rate applies to a shipment. Constraint (7) ensures that a line-item ordering cost is incurred if an item is shipped on a link and also imposes capacity limits on links. Constraint (8) ensures that only one cycle time applies to an item on a particular arc. Constraint (9) compactly ensures that order header costs are incurred when line-item order costs and, by virtue of constraint (7), flows exist on a link. Finally, constraints (10) and (11) impose restrictions on the numbers of open plants and warehouses, respectively.

\subsection{Shipment consolidation}

Shipment consolidation is concerned with determining the composition and shipping frequencies of shipments (also called groups). Optimal grouping leads to the lowest possible logistical cost.The key to the concurrent determination of flows and shipments is a 
transformation found in network flow analysis, namely, artificially dividing (or splitting) the total flow of product on each link into smaller groups. Each group includes only the products that have the same cycle time (shipping frequency), and the same transportation freight rate. All the products in a group are shipped together, thus comprising a shipment. The model is solved to determine the optimal shipments on each link in the network.

Using the notation of the model, assume, as an instance, that the optimal (or best) solution specifies optimal flows in which variables are positive-valued. This means that commodities 1 and 5 are, "first, both shipped on arc 2, and, second, both part of the same shipment on arc 2 . This shipment incurs the third freight rate and is shipped with the second shipping frequency applicable on arc 2 . Therefore, one of the optimal groups on arc 2 will include both items 1 and 5. It may be noted that the constraints of the model ensure that an item cannot belong to more than one group (i.e., shipment) on any particular link. This illustrates how the form of the decision variables of the model makes it possible to concurrently determine both optimal flows as well as optimal groups (shipments). In this context, permissible cycle times (shipping frequencies) belong to a discrete set that corresponds to the specifications or needs of logistics managers.

\section{CONCLUSION}

In the evolving logistics marketplace, winners understand that there is no single path to success. They overtake competitors by selecting an organizational model that best supports their corporate strategy. They also ensure that the strategy matches their targeted customer segments. To increase their competitive edge, leaders develop insights into customers' needs and purchasing behaviors. The end result is a highly focused organization with a well-defined business strategy, designed to deliver sustained growth and profitability. Lot of models are in theory for customization of logistics network. Here practical implementation of models like Centre of Gravity method, PEST Method, Vehicle Scheduling Method ,Transportation method applying Vogel's Approximation Method(VAM), Demand Forecasting by Linear Regression Analysis.

\section{References}

Benjamin J. An analysis of inventory and transportation costs in a constrained network. Transportation Science1989;23(2):177\}83.

BTRE (2001) Logistics in Australia: A Preliminary Analysis. Bureau of Transport and Regional Economics, Canberra, <http://www.btre.gov.au/docs/wp49_contents.htm>.

Bowersox, Donald J. and Closs, David J. and Cooper, M. Bixby (2002), "Supply Chain Logistics Management", McGraw-Hill

Bowersox, Donald J. and Closs, David J. and Cooper, M. Bixby (2002), "Supply Chain Logistics Management", McGraw-Hill

Blumenfeld DE, Burns LD, Daganzo CF, Frick MC, Hall RW. Reducing logistics costs at general motors. General Motors Research Report-5334, General Motors, Warren, MI, 1986.

Cooper, M.C., Lambert, D.M. and Pagh, J.D. (1997) Supply chain management: more than a new name for logistics, International Journal of Logistics Management, Vol. 8, No. 1, 1-13.

Chopra, S., Meindl, P. Supply Chain Management: Strategy, Planning, and Operation. 2001. Prentice-Hall, USA. 457

Creswell, J. W. (1998), “Qualitative inquiry and research design: Choosing among five traditions”, London Sage Publication

Klincewicz J. Solving a freight transport problem using facility location techniques. Operations Research 1990; 38(1):99\}109. 
Khumawala, B. M. (1972, August). An Efficient Branch and Bound Algorithm for the Warehouse Location Problem. Management Science, 18, B718-B731.

Melachrinoudis, E. \& Min, H. (2007). Redesigning a warehouse network. European Journal of Operation Research, 176, 210-229.

Thomas, A., and Mizushima, M. (2005), “Logistics training: necessity or luxury?”, Forced Migration Review, Vol. 22, p. 60. 